\title{
Research on the Grid Management Mode of Advanced Domestic Communities under the New Media Era
}

\author{
Guihua Liu \\ Southwest Jiaotong University \\ Chengdu, China \\ 15928526053@163.com
}

\author{
Yifan Yang* \\ Southwest Jiaotong University \\ Chengdu, China \\ 464298576@qq.com
}

\begin{abstract}
Grid management is the biggest measure of social management in the grassroots self-government process. I read a lot of journals about grid management. I mainly utilized of the literature analytic method and charting. This article will make an in-depth analysis of the grid management mode of advanced domestic communities in the context of the new media and try to solve problems such as unscientific grid division, low quality of grid staff and incomplete legal protection, and etc. attempting to explore a new path of "new" grid management for domestic communities from the predicament so as to realize the harmonious development of smart communities, [1]professional communities, and humanistic communities and to better serve the country's economic and social development.
\end{abstract}

Keywords-New Media; Advanced Domestic Communities; Community Grid; Mode

\section{RESEARCH ON GRID MANAGEMENT ModE OF} ADVANCED DOMESTIC COMMUNITIES

\section{A. Community Grid Management Mode in Beijing}

In 2004, Beijing took the lead in implementing the grid mode of urban management and put it into use. By the end of 2015, the grid management system has covered more than $90 \%$ of the streets and communities in Beijing. The community management mode of Beijing is "One Separation, Three Confirmation, and Two Goals”. Specifically, "One Separation" means that the functions of community neighborhood committees and social service stations are independent of each other. "Three Conformation" includes fixed personnel, fixed tasks, and fixed funds. That is to say, it is required that personnel should be consistent with tasks and tasks should be consistent with funds so as to avoid the problem of "inconsistent power and responsibility" and "inconsistent tasks and funds". The construction of a professional and high-quality team of community workers and the establishment of a newtype socialist community are the "Two Goals" of the community management mode in Beijing. ${ }^{[2]}$
Research on community grid innovation management of Chengdu (2016-RK00-00278-ZF)

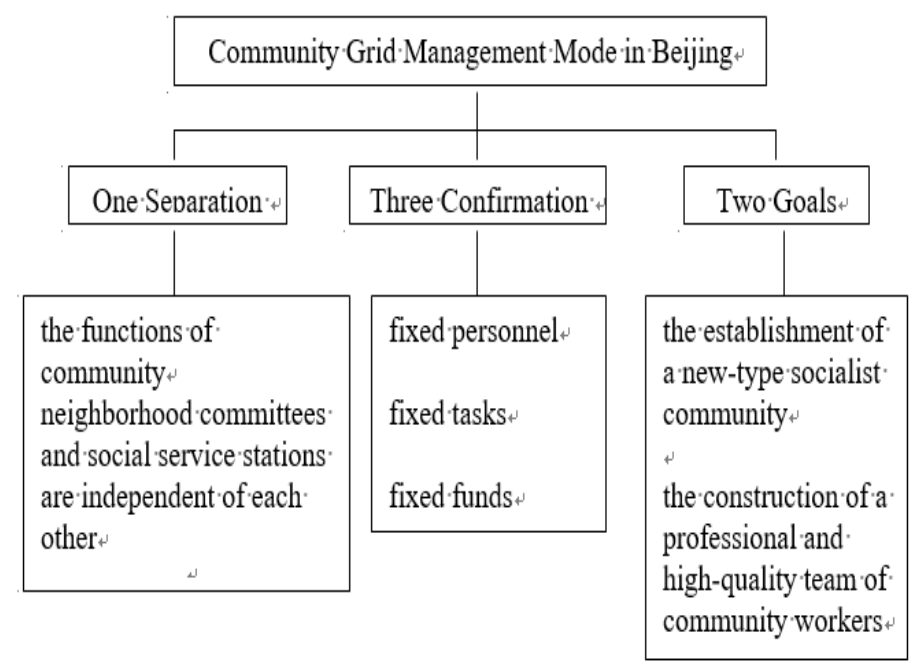

Fig. 1. Community Grid Management Mode in Beijing

The practice of grid management in Beijing began with the management mode of the 10,000-meter-unit grid in Dongcheng District. There are 17 streets and 205 communities in Dongcheng District, and the whole area is divided into 589 grids. In terms of grid management, Dongcheng District has established the Urban Management Supervision Center and the Urban Comprehensive Management Committee. They are mutually independent and restricted in functions to form a "dual axes" system of grid management, which includes a "supervision axis" and a "command axis". In addition, the community management structure of "one committee, three meetings and one station, and multiple participation in joint construction" has been adopted, forming a multi-faceted fivein-one pattern of community party committees, community residents committees, community residents conferences, community representative meetings, and community service stations.

\section{B. Community Grid Management Mode in Shanghai}

In 2004, the Shanghai Municipal Committee put forward the concept and requirements of community grid management for the first time. By the end of 2011, Shanghai has had a total 
of 34,619 10000-meter grids and 1,526 duty grids. At the end of 2012 , the duty grid has grown to $1,809 .^{[3]}$ In a series of explorations, Shanghai has formed a unique "Shanghai mode" featuring "two levels of government, three levels of management, and four levels of networks.”

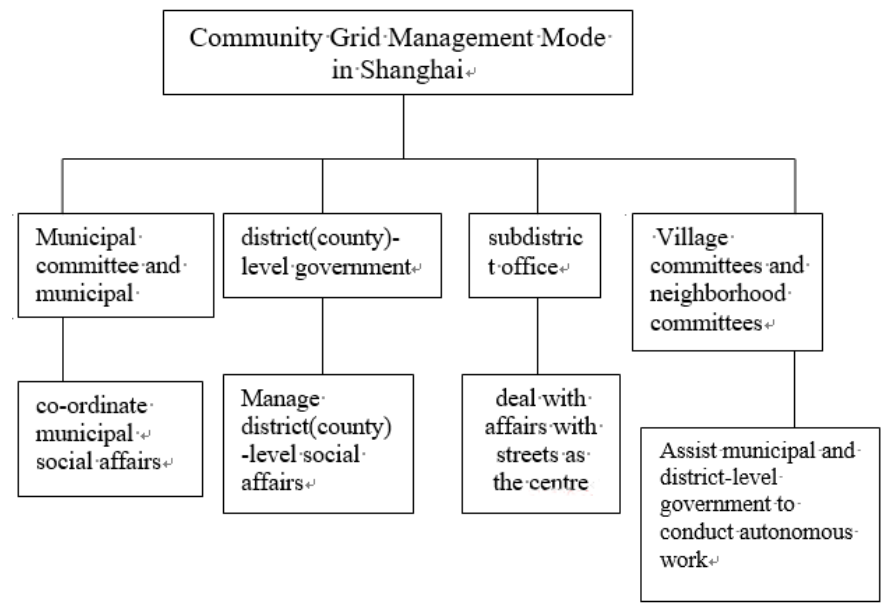

Fig. 2. Community Grid Management Mode in Shanghai

The mode of "Two Levels of Government, Three Levels of Management, and Four Levels of Networks" has separated the functions of government departments at all levels. In the community grid management, the municipal government is in the core position, and the district(county)-level government manages social affairs mainly according to the leadership and decision-making of the municipal government, and the street level is also incorporated into the grid management system as a level of quasi-government. At the same time, under the guidance of the policy of returning powers to the grassroots, village committees and neighborhood committees have been given corresponding powers to assist the government and the streets in autonomous work. Changning District advocates more refined management on the basis of the original mode. It makes use of information technology and means to link the "components" of the city with the "events" of the community. Therefore, the combination of "dynamics" and "statics" makes the problem-solving process more efficient. Among them, the Huayang Street in Changning District, with the "trip into grid" mode, adheres to the principle of "branch adjacent", dividing the Huayang community into four sub-grids, each sub-grid covering 5-6 general Party branches or Party branches in the residential area.

\section{Community Grid Management Mode in Yichang}

Yichang develops its mode based on emulating the successful experience of advanced domestic communities such as in Beijing and Shanghai. It has explored a new system called "One Orientation and Three Features", ${ }^{[4]}$ which uses "peopleoriented" as its value orientation, "informatization" as its platform support, "gridding" as its management method and "full process" as its service orientation. Eventually, it has found a mew road with local characteristics in the practice of community grid management--the "Yichang mode".



Fig. 3. Community Grid Management Mode in Yichang

Yichang adopts the principle of "delimitation of streets and lanes, appropriate scale, seamless coverage, and dynamic adjustment", with 200 to 300 households as the grid division standard, dividing 155 communities in the urban area into 1421 grids. ${ }^{[5]}$ Its grid management starts with a "One Pass and Two Systems" as a digital platform. "One pass" refers to the "community E pass," covering seven functions including comprehensive governance, information collection, and civil service. "Two Systems" refer to the "Community Comprehensive Information Collection System" and "Community Comprehensive Service Management System" which aim to achieve more refined and more comprehensive community services. ${ }^{[6]}$ Yichang has innovated a new grid management mode and built an intelligent system of social governance with big data as its axis. The work of each department is interconnected with the basic database and the grid management platform to follow up the grid management and people's livelihood services, realizing "one connection and two follow-ups" and improving the digitization of social management. In addition, it has created a "direct government purchase service” precedent for the community management innovation path.

\section{ENLIGHTENMENT FROM THE GRID MANAGEMENT OF Advanced DOMESTIC COMMUNITIES ON PROMOTING DOMESTIC COMMUNITY GRIDIZATION}

\section{A. Innovation Management, Service Enhancement, and Creation of a Smart Community}

Against the background of new media, social innovation management has gradually expanded from the concept of "smart city" to the construction of "wisdom community". Community grid management is a way to "wisdom community". The concept of "wisdom community" requires community grid management to increase the intensity of Internet affairs management and continue to optimize the construction of an information management platform. On the one hand, the content and function of the community information management platform are optimized. Meanwhile, the network platform cannot be limited to the PC, and it should be developed toward the mobile terminal. On the other hand, it is necessary to increase residents' awareness of the community's online platform and enhance the operability of the platform. For example, the development of community APPs, the interaction of community microblogs, the 
construction of community WeChat platforms, and the development of community forums can allow community residents to better integrate into the management of community informatization.

\section{B. Scientific Grid, Smart Manpower, and Building of a Professional Community}

Scientific design of grid is the key to community grid management. First of all, the division of the community grids should pay attention to the integrity of the grid coverage. Second, the division of grids must be different. It should be specific to different grid and examine the specific environment of its location and analyze its actual characteristics to assess the level, such as general management and key management. Finally, if the population or space area is taken as a criterion, the drawbacks of the community block management will be neglected. As residents are the unit the community, the construction of community grid management should fully consider the residents' population and behavior characteristics. Grid members are the souls of providing community services in the grid, and the primary task of building a grid staff team is to clarify the identity of the grid members and to incorporate the grid staff into the national civil service system. The second task is to formulate the job description of the grid staff. Only the responsibilities of the job are clearly defined will the efficiency of the grid staff be ensured. The third is to establish a scientific performance evaluation system for grid members and set up incentive mechanisms to optimize the compensation system.

\section{Party-Building Deepening, Platform Optimization, and Construction of a Humanistic Community}

The organic combination of community grid management and party-building work utilizes the refinement and informatization features of the grid management mode, giving full play to the leading role of community party committees in the community, and avoids administrative rigidities by advocating open leadership. The party building work in the community is a rebuilding of the residents' ideological level, and it is particularly important to innovate the management mode of the party members. Not only the working party members in the community should be included in the grid system, but also the retired party members should be added to the grid to achieve full coverage of the grid party organization to promote the development of community grid management. In addition to the construction of an intrinsic value system, the community can also create distinctive public cultural services and establish community "cultural stations", including the construction of various cultural, sports and entertainment venues and their facilities (chess rooms, community libraries, etc.).

\section{Consolidating Public Security, Improving Laws, and Creating a Harmonious Community}

The 18th National Congress mentioned that national governance and social management cannot be separated from the rule of law. As a powerful tool, law plays a role in regulating social behavior. The implementation of it in the community grid management can be realized through "one community with one legal counsel.” and the community can set up a legal consulting studio. As the main body of public security and prevention and control, the public security department should make full use of the policing formal police and community policing capital to integrate community resources into social security in accordance with the security situation in each area. The gridding of community policing is an important force to ensure community safety. On the one hand, information resources can be used to innovate the policing work platforms of various police stations and policing work platforms of a community nature. The integration of the residents of the grid into the unified management of the platform can make the policing work visible and controllable. On the other hand, community residents should be made more aware of public security and improve their self-prevention capabilities. The community can use the new media such as WeChat and QQ to conduct safety education for community residents. It can also adopt the form of "policing into the grid" to provide zero-distance household guidance for community residents and ensure the orderly management of the community to the maximum extent to realize the construction of a harmonious community.

\section{E. Returning Power to the Grassroots, Strengthening Autonomy and Striving for a Democratic Community}

The creation of a democratic community should focus on the election of community organizations. The specific implementation of the election will ensure that all residents of the community have the right to vote and to be elected, and eliminate bad habits such as fraud and bribery. Doing a good job in community elections will help strengthen the construction of grass-roots party organizations, improve the party's ability to govern, and give full play to the rights of residents of the community. In the practice of community gridding, constructing participatory and dynamic management is also the key to building a democratic community. First of all, there is a need for multiple participation. The "one-stop" and "one-window" community service centers are not only office halls to serve the people, but also being used as carriers for community participation to integrate into the construction of a democratic community. Then is the construction of community-based channels for public opinion. There is a need for channels where the residents' opinions can be collected, reflected and solved, so that residents can get feedback on the reasonable views. The most important thing is to mobilize the participation of community residents, and enhance their capacity of self-government.

\section{CONCLUSION}

The community grid management mode in some regions has become a model in community grid management development, but in regions with relatively backward economies grid management is still emerging as a new thing. However, against the background of social innovation and governance, with the opportunity of vigorous development of new media, social public management is experiencing continuous innovation, and the country has gradually promoted and improved community grid management from mega-cities, big cities, and small-and medium-sized cities. Obviously, Grid 
management has become the indicator of current social management trends.

\section{REFERENCES}

[1] Zhou Lun, Li Xuehui. Small Grid of City and Grand Stage of People’s Livelihood-a sample analysis of grid management innovation in Yichang, Hubei Province[J]. Contemporary Guizhou, 2012 (19)

[2] Qiu Xiaoli, Yu Jiahui. Practice and Reflection on Urban Community Construction in Beijing [J]. Chinese Administration, 2012(03)
[3] Chen Haisong, Ying Min. Practice of Comprehensive Urban Management: Grid and Big Linkage: Taking Shanghai as an Example[J]. Shanghai Urban Management, 2014(04)

[4] Guo Youming. Innovating to Construct a "One Orientation and Three Features” Social Management System [J]. Policy, 2012 (08)

[5] Chen Guilong. Creating a New Model of Grid Management in Yichang[D]. Informatization of China Construction, 2016(03)

[6] Zhang Yunmeng. Practice and Thinking of Community Grid Management in Yichang City[J]. New West (Theory), 2015(14) 